\title{
Exploring students' experience and perceptions of the Somatology extended curriculum programme at the Durban University of Technology
}

\section{Mokgadi Ursula Makgobole}

Chiropractic and Somatology, Durban University of Technology (DUT), Durban, South Africa mokgadim@dut.ac.za

https://orcid.org/0000-0001-6530-7079

\section{Stanley Chibuzor Onwubu}

Chemistry Department, Durban University of Technology (DUT), Durban, South Africa

21445599@dut4life.ac.za (Correspondence)

https://orcid.org/0000-0002-4499-1534

(Received: 10 July 2020; accepted: 30 December 2020)

\section{Abstract}

The South African Higher Education (HE) sector has faced scrutiny in recent years because of its low participation and high attrition rates. In an attempt to address this, institutions have introduced additional programmes such as Extended Curriculum Programmes (ECPs). In this study, we followed an interpretive research paradigm to explore students' experiences and perceptions of the somatology ECP at the Durban University of Technology DUT). Semi-structured interviews were conducted with 15 individual students out of the 69 graduates of the somatology ECP. The participants believe that social integration and reduced academic workload over an extended period contributed to their academic performance. The participants felt that support subjects such as writing skills and computer literacy and the work done by staff and mentors of the ECP facilitated their academic success. The findings from the study suggest that the somatology ECP was successful, too, in the social integration of students while preparing them for success.

Keywords: Extended Curriculum Programme, Higher Education, somatology

\section{Introduction}

The higher education landscape in South Africa continues to be plagued by low participation and high attrition rates (Fisher \& Scott, 2011). Consequently, the continued interest in strategies to ensure that the output of higher education meets the country's needs are understandable. Considering that South Africa's spending on education is one of the highest 
in the world at $6.2 \%$ of its GDP, according to the World Bank (2013), its low graduation rate of $15 \%$ has been described as unacceptable in comparison with higher education systems elsewhere (Badat, 2010; Fisher \& Scott, 2011; Lewin \& Mawoyo, 2014).

While the Council on Higher Education (CHE) (2013) has acknowledged that dysfunctional schooling must continue to be the focus of corrective effort, it, however, advocates that the HE sector should act on factors within its control to address the systemic conditions that are impeding student success. Currently, the debate in South African Higher Education (HESA) has moved from increasing student access to increasing student success (Department of Higher Education and Training, 2013; Higher Education South Africa, 2014; Lewin \& Mawoyo, 2014). According to CHE (2013, pp.16-17), “[I]t is widely accepted that student underpreparedness is the dominant learning-related cause of patterns of poor performance in HE." Consequently, the Department of Higher Education and Training (DHET), through its agencies and affiliates, HESA and CHE, has instituted interventions that aim to enhance the articulation gap between the student entering academic programmes and completing them successfully. While these have taken several forms (such as tutoring, mentoring, and the establishment of writing centres), the Extended Curriculum Programme (ECP) has been seen to be an enduring feature of an evolving HE system aimed at "enabling students to develop sound academic and social foundations for succeeding in HE" (CHE, 2013, p. 18).

Like every other university in South Africa, DUT was established to meet the diverse needs of its students and to prepare them to fit into the world of work and the social world during their course of study and after graduation. Although the ECP programme is being funded nationally by the DHET, each university, therefore, sets its own guidelines for running the programme in order to meet local realities and fulfil the demands of the curriculum.

Given the limited research done on ECP programmes offered at DUT, to date, no research has been done on the impact that the Somatology ECP has had on the success of its students nor on its failure to deliver results. Research on the performance of the ECP is important because Somatology not only aims to have students graduate but also targets the development of specific skills that are crucial for their employability. In light of this, this study aimed to explore the perception and experiences of ECP on students' academic success in the Somatology programme of DUT.

\section{Overview of the Somatology programme}

The word Somatology stems from the Greek word for the study of the body as Rammanhor (2015) has noted. The profession of Somatology has existed for decades. Prior to 1996, the qualification was known as the National Diploma: Beauty Technology. After 1996 the name changed to National Diploma: Somatology because Technikons wanted to differentiate their qualification from those of private institutions (Campbell, 2012). Somatology is currently offered at five Universities of Technology (UOTs) in South Africa and its curricula cover both theoretical and practical modules. The scope of practice includes basic and advanced face and body care, numerous massage techniques, aesthetic enhancement techniques, 
marketing, and managerial skills training (Department of Chiropractic and Somatology, 2017).

Upon completion of the course and the acquisition of the qualification, a somatologist may find employment in various fields such as in health and wellness centres, spas, pharmaceutical companies, on cruise liners, and in the retail sector. Also, they may seek work alongside dermatologists and plastic surgeons, become an entrepreneur or seek a position as a lecturer (Borg, 2009).

\section{Contemporary challenges in South African higher education}

For most students in developing countries like South Africa, a variety of factors such as poor academic literacy and inadequately resourced high schools heighten the challenges that students face in entering higher education (Chimbganda, 2011). This phenomenon has been noted in developed countries, too, when immigrants enter universities in these countries (Perez \& Holmes, 2010; Wingate \& Tribble, 2012). In South Africa, a different kind of situation has been created by the legacy of apartheid, a system that created wide inequality between the different race groups in South Africa with black South Africans bearing the greatest burden of extremely low employment and poverty, along with under-preparedness for higher education learning and subsequent low throughput in higher education, (Kraak, 2013). To this day, the inequality in the provision of education provision still exists and schools and their learners, disadvantaged by apartheid, still bear the scars of the past as Mouton et al. (2013) have pointed out. The argument put forward by these scholars explains the current educational challenges that plague South Africa. As they have stated, it is nearly impossible to separate the country's current educational challenges from the effects of the legacy of apartheid since it was this system that laid the foundation for the low enrolment rates of blacks in academic institutions and their poor academic performance when they do get admitted.

\section{Academic intervention programmes in South African higher education institutions (HEIs)}

Lewin and Mawayo (2014) have noted that student access and success are the primary concerns of HEIs throughout the world, and even more so now with the increasing globalisation of education and the strong efforts to increase rates of participation in HE. Murray and Nallaya (2016) reported that the demographic of students studying in universities today has become diverse in terms of their background, culture, age, socioeconomic status, and their entry pathways through which they arrived at university. According to Johnson (2017), the majority of these students are underprepared and this limits their access and their success. As a consequence, Academic Development Programmes (ADPs) such as the ECP, Foundation Programmes (FPs) and/or Access Programmes (APs) have been implemented 
globally by universities to facilitate the access and success of underprepared students (Dhunpath \& Vithal, 2012).

In South Africa, for example, FPs have been established in the past to widen access and promote success for disadvantaged students in higher education (Bass, 2007). Among these programmes, the Science Foundation Programme (SFP) and the University Foundation Programme (UFP) are used as a benchmark for FPs. The SFP was introduced in 1991 at the then University of Natal (Pietermaritzburg) now the University of KwaZulu-Natal (UKZN) (Grussendorff et al., 2004). The SFP offers students without matriculation exemption a yearlong programme. In it, students are offered subjects like physics, chemistry, biology, and academic communications (Bass, 2007). The students who complete the programmes successfully are allowed to enrol for any of the specifically related science degrees.

However, the UFP established in 1999 at then Nelson Mandela Metropolitan University, now Nelson Mandela University, offers streams leading to all areas of study_business, sciences and the Humanities - as Lithauer and Wood (2005) have reminded us. Typically, students are taught, as the core subjects, English for academic purpose and life skills.

These interventions are meant to assist students to cope successfully with the university curricula as well as to redress inequalities caused by the apartheid system (Case et al., 2014). Nevertheless, the SFP and UFP do not qualify for the Department of Education (DOE) subsidy for FPs (Bass, 2007). The lack of government subsidy available for these FPs may have prompted the development of the ECP.

\section{Effectiveness of ECPs}

The ECP assists students in transitioning from high school to university and facilitates their integration with other students who are in the full curriculum mainstream as well as facilitating the acquisition of academic literacy among other benefits (Borg, 2009; van Schalkwyk et al., 2010). According to CHE (2013), the ECPs are a South African higher education intervention designed to deal with systemic obstacles to equity and student success, particularly through addressing the articulation gap mentioned above that has been in existence in various forms for three decades.

ECPs started in the 1980s as academic support programmes aimed at enhancing access opportunities for "talented but underprepared students for them to achieve sound foundations for success in higher education" (CHE 2013, p. 70). The understanding then, as now, was that there is a gap between school-exit capacities and the requirements for success in higher education for some students. Over the past 20 years, this gap difference has been mainstreamed in the transformed higher education system as a way of achieving equity in, mainly, access. This means that many programmes at universities have course specific ECPs while some have general university ECPs.

ECPs are believed to have been successful in enhancing academic access particularly for the group of students who would otherwise not have managed to cope with the rigours of 
traditional curricula (CHE, 2013). Chetty (2014), in assessing the impact of ECP in the Physics programme, argued that this has been a success, not only in achieving equity of access but in enhancing student performance. Bas (2007) reported on the similar success of the ECP in Dental Technology at DUT.

\section{Student experiences of the ECPs}

In a study exploring the experiences of an ECP in Humanities at UKZN, the students perceived that it contributed to their social and academic integration which, in turn, influenced their academic success (Tyson, 2010). Similarly, in a report by Nala (2010), the ECP students noted that the programme equipped them with the academic writing skills needed to excel in higher education. This meant that they were able to outperform and even assist their mainstream peers in their academic writing.

Nevertheless, it has been reported that ECP students studying Nursing at DUT felt stigmatised and lacked confidence because of being placed in the programme (Sibiya \& Mahlanze, 2018). Their work supports that of Johnson (2017) who noted that this sense of stigmatisation and a lack of confidence among the ECP students gravely affected their motivation and their chances of success. Other studies, however, have found otherwise. ECP students at the University of Stellenbosch did not feel stigmatised for being placed in the programme (De Klerk et al. 2005). In corroboration, Bass (2007) found little evidence to suggest that stigmatisation had a negative impact on ECP students in the Dental Technology programme at DUT.

Equally importantly, Johnson (2017) found that the duration of the ECP was of concern to the students given their financial challenges and the stigma associated with being in the programme. According to his findings, many were dissatisfied, they questioned the value of the extra year they had to spend on the programme and considered this a waste of time in terms of their career and in their progress in life. And, equally concerning, and despite the appreciation expressed by the students that the ECP eased their transition from high school to university, many considered the ECP programme as having not been challenging enough during their second and third years. According to Johnson (2017), the ECP students noted that they felt that they were lazy because of the reduced workload compared to what was expected of the mainstream students. As a consequence of this, the students noted that they made fewer efforts in their academic work.

\section{Conceptual framework}

While we appreciate all the scholarly work that has been done on student access and success, we hope that employing Tinto's (1975) Student Integration Model (SIM) will add a new angle to the current debate. The development of Tinto's SIM was inspired by Emile Durkheim's suicide theory. According to Durkheim, an individual's likelihood of committing suicide is linked directly to his/her level of integration in or isolation from society (Tinto, 
1975). The more isolated $\mathrm{s} / \mathrm{he}$ is, the more likely s/he is to commit suicide but the more integrated into society, the less likely to do so.

Tinto's model takes the academic environment as a microcosm of society-a society in its own right. Therefore, the level of integration a student experiences in relation to either the social or academic aspects of the academic environment will determine the extent to which $\mathrm{s} / \mathrm{he}$ is prone to attrition. The more isolated in either the social or academic aspect the student is, the more likely s/he is to drop out. However, for Tinto, the balance in levels of integration between these two aspects of academic society is also important since any form of imbalance in integration can cause similar effects to those resulting from isolation such as suicidality (Tinto, 1975).

Over the past three decades, Tinto's model has been revised by scholars analysing the dynamics of student goal commitment and the ability of the institution to meet the needs of the student. According to Schreiber et al. (2014), Tinto's revised student integration model (1997) is linked to the pre-university entry attributes to the institutional experience such as family background, skills and abilities, and prior schooling. These scholars noted that the perceived association between a student's pre-university entry attributes and his/her institutional experience ultimately determines his/her educational outcome, retention, and success. Godsell (2013) argued that integrating students' experiences and history into the educational scenarios would empower them with the critical thinking skills relevant to their experiences and prepare them to resolve their own socio-economic and political problems. Dhunpath and Vithal (2012) acknowledged that the bridge the institution creates between a student's culture of origin and his/her immersion is considered to be very significant to students. These authors therefore proposed that the institution must identify, through investigation from the students, what they need by first of all understanding to what they attribute success or failure.

However, critics of Tinto's model have argued that social and academic integration do not act as reliable indicators for persistence rates among non-traditional (such as distance learning, mature, minority, and returning) students (McCubbin, 2003). Despite the apparent limitation of Tinto's approach, the model we use is streamlined to add value to exploring the perception of ECP on students' academic success and their experiences in the somatology programme. This model allowed assessment of the participants' pre-entry attributes, their institutional experience, and their integration levels in view of their pre-determined goal commitments to becoming somatologists.

\section{Methodology}

In order to explore the perceptions and experiences of the somatology ECP graduates, we used an interpretivist paradigm which followed a qualitative research approach. We chose this because it allowed us to explore the experience of the ECP graduates of the somatology programme. According to Cooper and Schindler (2014), an interpretivist paradigm is centred 
on people's behaviours and how they make sense of the world through sharing their experiences with others through the medium of language.

\section{Research setting and sampling}

We conducted this study with graduate students of the somatology ECP at DUT. This ECP is a four-year full-time programme offered to underprepared students who show potential to succeed in higher education to gain access to it. Students in both the three-year programme (SCM) and the four-year programme (ECP) register for the National Diploma: Somatology. However, the ECP curriculum splits the first year of the programme over a period of two years. As illustrated in Table 1, students gain admission into the somatology programme by meeting the minimum requirements after writing a Standardised Assessment Test for Access and Placement (SATAP).

Table 1

Entrance requirements for the Somatology programme.

\begin{tabular}{|l|l|l|l|}
\hline & NSC & NSC Senior Certificate \\
\hline Subject & NSC Rating & HG & SG \\
\hline English & 3 & E & C \\
\hline life sciences/ biology & 4 & D & B \\
\hline \multicolumn{2}{|l}{ maths literacy or mathematics } & 3 & \\
\hline English (first additional language) & 4 \\
\hline
\end{tabular}

The sampling strategy followed a probability sampling process using simple random sampling. According to Check and Schutt (2011) simple random sampling ensures that every potential participant has the same probability of inclusion in the study. Between 2005 and 2010, 122 students originally enrolled in the ECP. Of this number, 69 graduated from the programme with a qualification thus representing a $56.56 \%$ pass percentage of enrolled students. The selection involved a process in which a sampling frame was established that included 69 paper slips of the same size and colour, each one bearing a participant's name. Following Polit and Beck (2004), a blindfold selection was made, and 30 names were drawn. Each coded participant was contacted telephonically and invited to an interview at a convenient date, time, and chosen venue.

\section{Data collection}

Data was collected via semi-structured individual interviews. Although all the selected participants agreed to participate in the study, only 15 were interviewed individually because of data saturation, which has been defined by Guest et al. (2006), as the point at which no new information or themes are observed in the data. All interviews were conducted by the researchers and lasted from 30 to 45 minutes, depending on the dynamics of each. The interviews were recorded using a smartphone (LG-G4) and notes were written as back-up for the recordings as advocated by Maree (2007). All recordings were transferred to a USB 
immediately after the interview and deleted from the phone to ensure confidentiality and the security of the data. The interview schedule consisted of pre-determined questions to elicit appropriate responses about the interviewees' experiences with and perceptions of ECP.

- When you were accepted into the somatology ECP did you know why you were placed in the programme?

- How did you feel about being placed in the programme?

- Did you perceive any differences in your lecturer's attitude between ECP and mainstream students when you sat in class together?

- What was your subject lecturer's attitude towards ECP students?

- Which aspect of the ECP did you find beneficial in adjusting to your university studies?

- Which aspect did you not find helpful?

- Are there any modules you would have liked to have been added for you to have had a better experience of the ECP?

- Would you recommend a student to enrol in the somatology ECP programme rather than in the mainstream? Why?

Data analysis

The data generated from the individual interviews was transcribed and analysed using thematic content analysis that focused on identifying themes or patterns that emerged from different responses in line with the guideline process developed by Saldaña (2015). This entailed using operating coding to create categories to theme the data. All analysis was performed with the aid of Nvivo v11 software (QSR International Pty Ltd., 2015).

\section{Trustworthiness}

The trustworthiness of the study is supported by our describing the findings in detail using the data generated during the discussion verbatim. Furthermore, the accuracy of the transcription was ensured by listening to the recordings again and comparing these with the transcription. Participants were allowed to read the transcription if they wished to and could validate that what was transcribed correlated with what they had said.

\section{Ethical considerations}

Before the collection of data, ethical approval was obtained from the university ethics committee (REC 88/14). Permission to conduct the study was obtained from the Research Director at the Durban University of Technology and the Head of the Department of Somatology. An information letter was provided to the participants and written informed consent was obtained from all of them. The confidentiality of the participants was assured by assigning a code in place of their names. 


\section{Results and findings}

Table 2 highlights the themes and subthemes that were extracted from the study findings.

Table 2

Identification of themes and sub-themes

\begin{tabular}{|c|l|}
\hline Theme & Sub-theme \\
\hline $\begin{array}{l}\text { 1. Factors influencing student throughput } \\
\text { and academic performance. }\end{array}$ & $\begin{array}{l}\text { Influence of social integration on ECP } \\
\text { student throughput }\end{array}$ \\
& $\begin{array}{l}\text { Influence of reduced academic } \\
\text { workload and excess time on ECP } \\
\text { student throughput }\end{array}$ \\
\hline $\begin{array}{l}\text { 2. Factors influencing student academic } \\
\text { success. }\end{array}$ & $\begin{array}{l}\text { - Support subjects } \\
\text { - Staff and mentor support }\end{array}$ \\
\hline
\end{tabular}

** Student academic success is premised on the FTE Passed divided by FTE Enrolled expressed as a percentage.

*Throughput and academic performance denote the tracks of a cohort of students registering for the first time at a tertiary institution and completing in minimum time ( 3 years, minimum time +1 , minimum time +2 , etc).

\section{Theme 1: Factors influencing ECP student throughput rate and academic} performance

The underlying motive behind the ECP is to create access and success for previously disadvantaged students. During the interviews, all participants kept referring to the ECP as the "Wellness" programme (Wellness refers to the academic literacy aspect of the Wellness subject). The term "wellness" was used to identify themselves within the ECP programme. It was used to distinguish themselves from the mainstream Somatology (SCM). As Participant L began, "As a wellness student ..."

Whether the use of "wellness" as a term to identify ECP had a positive or negative impact on individual participants was unclear and the significance of this will be discussed later in this article.

\section{Sub theme 1:1 Influence of social integration on ECP student throughput}

A minority of the interviewees who had graduated from the ECP stated that being on the ECP served as an academic advantage when compared to the mainstream programme. We quote two students here.

It was good, we interact a lot as an ECP class, compared to when we are grouped together with the mainstream, other [mainstream] students lost their confidence. But with ECP classes we did a lot of presentation[s] and helped to prepare so when we did presentations with mainstream, we were confident and scored better marks than them. (Participant M) 
The fact that we were small in class [meant] we became friends and motivated each other as some of us stayed at res together and we still are friends even now. . we were like a small family, home away from how as teacher Y would say. (Participant F)

From participant's F extract it is apparent that good social integration was evident among the ECP students. This was pointed out by the study participants interviewed as one of the factors that had influenced their academic performance.

\section{Sub theme 1:2 Influence of reduced academic workload and excess time on ECP student throughput}

ECP students have a reduced academic workload based on the belief that a reduced workload will improve student academic performance. A majority of the students remarked on this and appreciated the fact that participating in a programme with a reduced workload gave them more time to focus on their studies and increased their chances of passing all credit-bearing subjects. For Participant D,

And when you're getting more subjects then you are bound to fail or you're prone to failing, but if you're getting [fewer] subjects you perform better.

For Participant I,

Because I had a lot of free time on my hands, I had a lot of time to study the subjects in-depth [and] as there were only 3 [subjects] [I passed] with distinctions.

Significantly, a small minority of students were of the view that the reduced workload had little impact in their academic performance.

To be honest, I did not see it bringing any benefits to me. I think it was one year that I lost out on. (Participant C)

The modules that were presented in the ECP [were] quite simple. It was modules that I could have done in a fulltime programme, [and] it was not a very full programme where there was a lot of modules. So, there was a lot of free time which was not good enough because you go to campus and you expect to have to have a full day of work and then you have free time in between and then you have to find something else to do. (Participant F)

Factored into the ECP is the intention to allow students free time which they can use to integrate more fully into campus life. However, this was not always appreciated by a few ECP students.

I had end[ed] up going, if I didn't go to the cafeteria to get something to eat, I end[ed] up going to [the movies]. So, it's not a good thing to have that free time because you can lose track of time and then some people would feel like you know what, let's just 
go watch a movie and miss the next lecture. So, having those big breaks in between modules is not the best idea. (Participant G)

Participant G's position was corroborated by that of Participant I who expressed a similar view.

The first couple of, like probably the first two months [were] interesting [because of] having a lot of time on your hands, not being busy as much, but then after that, it started to just get annoying because you study and then that's it. Throughout the rest of [the] day you would just be done, finished. So, it started out as nice, you have a lot of time on your hands and then, and then it just, everything started to be repetitive. You wake up, go to school and then after that you are done for the rest of the day. So, it started to get boring and very slow. (Participant I)

However, Participant $\mathrm{J}$ had a different view from participants $\mathrm{G}$ and $\mathrm{I}$.

Being new in Durban and coming from a rural area, after classes I would go to the computer lab or the library with some of my Wellness mates to do assignments. If we didn't have assignments, we would go to Steve Biko or ML Sultan for lunch. Sometimes I explore[d] Durban with my new friends (chuckle). During my time here I also played for the DUT female soccer team.

The most noteworthy finding pertinent to this theme is that the way in which students managed their time was critical to their academic performance. It was extracted from the interview data that too much available time for academic activities resulted in laxity among some of the participants.

\section{Theme 2: Factors influencing student success}

The main goal of the ECP is to create access to those who had been academically disadvantaged at their schools and to facilitate success through structuring the programme over a longer time period as Johnson (2017) has noted. Thus, the interview questions sought to find out from the participants whether or not the ECP influenced their academic success. The participants' remarks were as varied as were their experiences.

\section{Sub-theme 2:1 Support subject}

Some of the students stated that the programme had a beneficial effect on their social and computer skills. Some claimed that because they came from the rural areas, they lacked basic computer skills and the programme helped to bridge the knowledge gap.

The first thing that was exciting was that I was going to do computer. I [come] from [a] rural area so our schools didn't have that kind of equipment. So, doing computer [literacy], it was ja . . . and there are modules that help [you] to understand about tertiary life including academic literacy, library information studies, [that] teach you 
how to get information from the library, and in academic literacy there are topics that [have] debates on tertiary life that helps you to interact with students. (Participant E)

Participants D and $\mathbf{J}$ emphasised how the ECP lecturer assisted in academic and work preparedness.

Plus, okay, I just want to note this, there's these subjects, they're called. . . what do you call these subjects, I forgot it, it's Wellness 1 and Wellness 2, the lecturer was X. So, she sort of like teaches you how to plan for your studies and how to reflect on such things as [are] happening in school and how to like be. . . or to assimilate in a tertiary level. So that sort of like helps. (Participant D)

Yes, I can say they [lecturers] did help me, because sometimes you have to be challenged to think about other stuff you do not consider on [a] daily basis, like when it comes to looking out for work, how to draft a professional looking Curriculum Vitae, and how to present yourself when you are appointed for an interview, and all [that] stuff. (Participant J)

However, two participants were not challenged by being placed on the ECP.

I find [the subject] Wellness not challenging. I find it, I really do find that it's a waste of time. Most of what we did, I had already done in high school. I already knew them. (Participant F)

It was boring as when we attended subject like ANP Wellness and Nutrition Wellness. They would repeat the same thing we did when we were with the mainstream.

(Participant B)

It is worth noting upon reflection that participants who did not find ECP support subjects beneficial were English first language speakers while second language speakers of English found it beneficial. The acceptance of English first language students into the ECP would appear to deviate from its raison d'être.

\section{Sub-theme 2:2 Staff and mentors}

The integration of students into the university and the somatology programme identified by the students was achieved by the collaborative relationship between mentors and lecturers and the ECP students.

Participant $\mathrm{G}$ remarked that lecturers and mentors were cooperative in ways that allowed students to settle well in school.

I think mentors played an instrumental role because as much as they gave you [a] guideline of okay this is what you can do, and if you are struggling or you sense a bit of discrimination or anything then you can contact them, it was, lecturers . . I mean mentors [who] played a significant role in just being there for you as a first year and 
as well as an ECP, because if I am not mistaken the mentor we had was also an ECP [senior ECP student] so she sort of understood what happens in ECP so you could go to her anytime to basically just talk to you if you [were] finding anything that [was] not right or you [were] struggling or anything. So apart from the modules, I really think mentors played a good role for ECP students.

Participant F echoed student G's position.

The mentors, I found that they helped me a lot because at times I wouldn't understand you know when you first get into a programme ... so they helped me a lot, the mentors. They helped me understand the ... whole programme of the subjects and all those things.

\section{Discussion}

The purpose of this study was to explore the perceptions and experiences of the ECP graduates in the Department of Somatology. As mentioned above, Tinto's (1975) social integration model was used as the underpinning theoretical basis in understanding the perceptions as well as the experiences of the ECP students.

The research results showed that the majority of the participants attributed their social integration into higher education to the ECP. With the help of the ECP, the students felt good, interacted better in ECP classes, felt that they were well oriented to the tertiary education lifestyle, and had a good relationship with and support from academic staff and peers. In addition, the students developed their own identity as Wellness students, despite the negative connotations of being thus identified, which gave them a sense of belonging. The "Wellness identity" was probably used by the lecturers to distinguish the mainstream somatology students and the ECP. As highlighted in the Department of Chiropractic and Somatology's Handbook for Students (2017), the Wellness module is offered only to the ECP cohort in their first and second year in the dapartment.

From the foregoing, and consistent with Tinto's social integration model (1975), it is clear that the participants' perception of the ECP reflects that they were socially integrated into the institution and this, in turn, promoted better student retention and success. This is in agreement with Tyson (2010) who reported that the ECP contributed to students' social and academic integration which, in turn, influenced their academic success. Furthermore, the somatology students' perceptions indicate that they were quickly oriented to university life and that this had contributed to their success. The support systems students developed with fellow students and staff members is a factor in the ECP's success. The smaller sizes in the ECP classes enabled the formation of close relationships among the students as well as between students and lecturers that are difficult to cultivate in mainstream studies since large class sizes do not allow the lecturer to interact with all students nor meet their individual needs. 
Apart from social integration, another factor that helps to explain the success of the ECP students may be linked to the academic integration experienced by these students. As theorised by Tinto (2008), there are two aspects to academic integration. The first is to meet the standards of the institution, and the second relates to the students' ability to identify with the beliefs, values, and norms of the academic system (Schreiber et al., 2014). The somatology students interviewed were of the view that the ECP non-credit bearing subjects that were part of the programme such as academic literacy and computer skills had helped them to learn to write academically and to use computers thus bridging their knowledge gap since they had had no experience of computers nor of library facilities. When comparing themselves to mainstream students they felt that they were better equipped with the kinds of skills that their mainstream counterparts lacked. Similar findings were reported by Nala (2010) who noted that ECP equipped students with the academic writing skills needed to excel in higher education. As mentioned earlier, Nala's (2010) participants were able to outperform and even assist their mainstream peers in the area of academic writing. This perhaps might also have contributed to the ECP students' success in the somatology programme.

The provision of a dedicated ECP coordinator and senior student mentors contributed to the integration of students into the life of the university as well as into the somatology programme and consequently contributed to ECP student success. It emerged that having mentors and a dedicated ECP coordinator (a staff member) allowed students to have one-onone attention to help enhance their understanding of subject content and to help with academic and social integration. Julius (2017) revealed that ECP students in his study appreciated the relationship with the lecturer and the rest of the ECP class. He noted that the students' constant interactions with one another and the genuine family-oriented mindset provided the students with a sense of belonging. This supports Tinto's (2008) finding that the ability of students to identify beliefs, values, and norms of the academic system contributes to academic performance and, consistent with Julius's (2017) point, this builds trusting working relationships.

With regard to mentors, great emphasis was placed on mentors getting to know each student better on an individual level. Some ECP graduates made reference to their experiences of the mentors who were themselves graduates of the ECP. Consequently, students found it easier to identify with and relate to them and see them as people to whom they could look up and who understood what they were going through and were able to advise them accordingly. This notion echoes Donald's (2002) observation that having important people in their lives greatly enhances knowledge acquisition as well as academic development in university students. Giving more credence to this, Julius (2017) reported that a caring attitude and supportive learning environment encouraged ECP students to excel academically since they did not want to disappoint their mentors and thus disparage the time and effort invested in them by their mentors; this helped to unlock their hidden potential. 


\section{Conclusion and future directions}

In conclusion, and although the views of the participants in the study experiences of the ECP programmed differed slightly, the majority of the perceptions of the programme were positive. The participants held the view that social integration and reduced academic workload over an extended period contributed to their academic performance. It was also noted that support subject like writing skills and academic literacy as well as the support received from the staff and mentors that helped to facilitate their social integration in the institution all contributed to their academic success. Given the role the academic staff played in the overall achievement of these students, a future study will seek to examine the perceptions of SCM students and academic staff regarding ECP to help determine the value and necessity of the somatology ECP.

\section{References}

Badat, S. (2010). The challenges of transformation in higher education and training institutions in South Africa. Paper Commissioned by the Development Bank of Southern Africa.

https://www.ru.ac.za/media/rhodesuniversity/content/vc/documents/The_Challenges_ of_Transformation_in_Higher_Eduaction_and_Training_Institutions_in_South_Afric a.pdf.

Bass, G. H. (2007). An investigation of the perceptions of learners and staff in respect of the dental technology extended first year programme (Unpublished master's dissertation). University of KwaZulu-Natal, Durban, RSA.

Borg, D. R. (2009). The effects of the extended curriculum programme on the social identity of students. (Unpublished master's dissertation). University of KwaZulu-Natal, Durban, RSA.

Campbell, D. E. (2012). The perceived proficiency of newly qualified Somatology graduates in using electrical equipment in modern health and skin care industry (Unpublished master's dissertation). University of Johannesburg, Johannesburg, RSA.

Case, J. M., Smith, L. C., \& Van Walbeek, C. (2014). Assessing the effectiveness of academic development programmes: A statistical analysis of graduation rates across three programmes. South African Journal of Higher Education, 28(2), 624-638.

Check, J., \& Schutt, R. K. (2011). Research methods in education. SAGE.

Chetty, N. (2014). The first-year augmented programme in physics: A trend towards improved student performance. South African Journal of Science, 110(1/2), 1-9. https://doi.org/10.1590/sajs.2014/20120096. 
Chimbganda, A. B. (2011). Discovering academic literacy skills in English of first year ESL. International Journal of Linguistics, 3(1). https://doi.org/10.5296/ijl.v3i1.903.

Cooper, D. R., \& Schindler, P. S. (2014). Business Research Methods. McGraw-Hill.

Council on Higher Education. (2013). A proposal for undergraduate curriculum reform in South Africa: The case for flexible curriculum structure. Council on Higher Education. http://www.che.ac.za/sites/default/files/publications/Full_Report.pdf.

De Klerk, E., Schoeman, A., van Denventer, I., \& van Schalkwyk, S. (2005). The extended degree programme at Stellenbosch University (1995-2004): An impact study (Unpublished research paper). University of Stellenbosch, Stellenbosch, RSA.

Department of Higher Education and Training. (2013). Annual Report 2012/13. DHET. http://www.dhet.gov.za/Commissions\%20Reports/Annual\%20Report\%202012\%20$\% 20201$

Department of Chiropractic and Somatology. (2017). Handbook for Students. Durban University of Technology.

Donald, J. G. (2002). Learning to think: Disciplinary perspectives. Jossey-Bass Inc.

Dhunpath, R., \& Vithal, R. (2012). Alternative access to university. In R. Dhunpath \& R. Vithal (Eds.), Alternative access to higher education: Underprepared students or underprepared universities? (pp. 2-20). Pearson.

Fisher, G., \& Scott, I. (2011). Closing the skills and technology gap in South Africa. Background paper 3: The role of higher education in closing the skills gap in South Africa, 1-54. https://doi.org/10.1177\%2F0021909616657369

Godsell, G. (2013). Overview and welcome in education overcoming innovation. Focus (The Journal of Helen Suzan Foundation), 68, 2-5. https://admin.hsf.org.za/publications/focus/focus68/\%280\%29\%20G.\%20Godsell\%20 INTRO.pdf.

Grussendorff, S., Liebenberg, M., \& Houston, J. (2004). Selection for the Science Foundation Programme (University of Natal): The development of a selection instrument. South African Journal of Higher Education, 18(1), 265 -272.

Guest, G., Bunce, A., \& Johnson, L. (2006). How many interviews are enough? An experiment with data saturation and variability. Field methods, 18(1), 59-82. https://doi.org/10.1177/1525822X05279903.

Higher Education South Africa. (2014). South African higher education in the 20th year of democracy: Context, achievement and key challenges. HESA. https://static.pmg.org.za/140305hesa.pdf. 
Johnson, U. (2017). Success or failure? Student experiences of the extended curriculum programme (ECP) in the College of Humanities (Unpublished doctoral dissertation). University of KwaZulu-Natal, Durban, RSA.

Julius, C. (2017). Nursing students' perceptions of an extended undergraduate curriculum programme within a higher education institution in the Western Cape Province (Unpublished master's dissertation). Stellenbosch University, Stellenbosch, RSA.

Kraak, A. (2013). State failure in dealing with the NEET problem in South Africa: Which way forward? Research in Post-Compulsory Education, 18(1/2), 77 -97. https://doi.org/10.1080/13596748.2013.755819.

Lewin, T., \& Mawoyo, M. (2014). Student access and success: Issues and interventions in South African universities. Inyathelo Publishers.

Lithauer, P., \& Wood, L. A. (2005). The 'added value' of a foundation programme. South African Journal of Higher Education, 19(5), 1002-1019.

Maree, K. (2007). First steps in research. Van Schaik Publishers.

McCubbin, I. (2003). An examination of criticisms made of Tinto's 1975 student integration model of attrition. https://www.psy.gla.ac.uk// steve/localed/icubb.pdf

Mouton, N., Louw, G., \& Strydom, G. (2013). Present-day dilemmas and challenges of the South African tertiary system. The International Business \& Economics Research Journal, 12(3), 285. https://doi.org/10.1080/01576895.2015.1050677.

Murray, N., \& Nallaya, S. (2016). Embedding academic literacies in university programme curricula: A case study. Studies in Higher Education, 41(7), 1296-1312. https://doi.org/10.1080/03075079.2014.981150.

Nala, N. (2010). The impact of the extended curriculum programme and students' experiences of the programme at the University of KwaZulu-Natal (Unpublished master's dissertation). University of KwaZulu-Natal, Durban, RSA.

Perez, D., \& Holmes, M. (2010). Ensuring academic literacy for ELL students. American Secondary Education, 32-43. http://www.jstor.com/stable/41406160.

Polit, D. F., \& Beck, C.T. (2004). Nursing research: Principles and methods. Lippincott Williams \& Wilkins.

NVivo 11. (2015). NVivo Qualitative Data Analysis Software. Version 11. QSR International Pty Ltd.

Rammanhor, K. (2015). An analysis of the somatology programme offered at South African Universities of Technology to determine whether it meets the needs of industry (Unpublished master's dissertation). Durban University of Technology, Durban, RSA. 
Saldaña, J. (2015). The coding manual for qualitative researchers. SAGE.

Schreiber, B., Luescher-Mamashela, T., \& Moja, T. (2014). Tinto in South Africa: Student integration, persistence and success, and the role of student affairs. Journal of Student Affairs in Africa, 2(2). https://doi.org/10.14426/jsaa.v2i2.64

Sibiya, M. N., \& Mahlanze, H. T. (2018). Experiences of facilitators regarding the extended curriculum programme offered at a higher education institution in the province of KwaZulu-Natal in South Africa. Curationis, 41(1), 1-6. http://dx.doi.org/10.4102/curationis.v41i1.1895.

Tinto, V. (1975). Dropout from higher education: A theoretical synthesis of recent research. Review of Educational Research, 45(1), 89-125. https://doi.org/10.3102\%2F00346543045001089.

Tinto, V. (2008). Learning better together: The impact of learning communities on the persistence of low-income students. In Proceedings of Opportunity Matters. Citeseer, 5-21. http://citeseerx.ist.psu.edu/viewdoc/summary? https://doi.org/10.1.1.472.8470.

Tyson, D. R. (2010). Examining the impact of the Humanities Access Programme 2001 to 2004: Throughput rates and students' perceptions of the programme (Unpublished master's dissertation). University of KwaZulu-Natal, Durban, RSA.

Van Schalkwyk, S., Bitzer, E., \& Van der Walt, C. (2010). Acquiring academic literacy: A case of first-year extended degree programme students. Southern African Linguistics and Applied Language Studies, 27(2), 189-201. https://doi.org/10.2989/SALALS.2009.27.2.6.869.

Wingate, U., \& Tribble, C. (2012). The best of both worlds? Towards an English for academic purposes/academic literacies writing pedagogy. Studies in Higher Education, 37(4), 481-495. https://doi.org/10.1080/03075079.2010.525630.

World Bank (2013). Government expenditure on education as \% of GDP \%. http://www.http://data.worldbank.org/indicator/SE.XPD.TOTL.GD.ZS. 